\title{
Digital Marketing In Pharmaceutical Sector
}

\author{
Ganesh R. Bharskar*1, SuhasS. Siddheshwar ${ }^{1}$ \\ Pravara Rural College of Pharmacy, Pravaranagar \\ Phone No.:+91 8766845734 \\ Email: ganeshb7748@gmail.com
}

"Digital" became an essential part of daily life. All the sectors were going to adapt more quickly to the digital world. The pharmaceutical industry, but except for the website has not been able to implement digital marketing entirely. There are many problems facing the pharma business when it comes to marketing. In this generation more pharmaceutical companies are using social media sites or ecommerce sites as a medium for digital marketing. That allows the customers to purchase products online. Several companies are trying to understand digital's true value whilst others are incorporating it into the wider marketing strategy. To raise their brand awareness, pharmaceutical companies will join those influencers in search of new ways to market their products. For example, if a pharmaceutical company approaches Asthmapatients then the influencer who is very involved on any social media platform and had experienced the same disease in the past can be contacted effectively to gain the interest of Asthmasufferers. In the case of medical products or medical devices, influencers may also be useful. All the firms, however, cannot sell products online because they produce prescription drugs which cannot be sold online. To connect with clients, YouTube, daily motion, Instagram, Twitter and Facebook were used.Quantum Pharmaceuticals and The Specials Lab, pharmaceutical companies located in the North East, offer online purchasing of special medicines that facilitate e-commerce and online marketing. KEYWORDS: Pharmaceutical marketing, digital marketing, digital marketing strategies, epharm, social media.

\section{INTRODUCTION:}

There are some firms that are very creative in terms of technical innovation, but the lack of good case studies on digitization in the pharmaceutical industry restricts the use. The Drug industry is not so well suited to online marketing. The sector's conservative conduct, coupled with unpredictable legislation, held back the pharmaceutical sector as advertisers rushed online in banking, professional services, manufacturing and business services. Nevertheless, online professional and patient communities have grown to accommodate the increasing use of internet, social media as well as online information by patient's healthcare professionals (HCP), key opinion leaders (KOL), and the broader medical community, instigating pharmaceutical companies to invest and test digital marketing approaches under industry guidelines. Interestingly, this is one of the best marketing tactics on social media channels that can help pharmaceutical companies boost their brand image. For all organizations which want to thrive at this digital age, digital marketing is critical. Modern ads, including Twitter, Youtube, prescription Bing and healthcare, are expected to grow to $\$ 10$ billion by 2020.This promotional budget is 13 points above what companies currently invest. 


\section{DIGITAL MARKETING IN INDIAN PHARMACEUTICAL INDUSTRY}

Digital marketing is the developmental stage in Indian pharmaceutical industry. Pharmaceutical companies are using technology-based services, helping patients learn more about their conditions and helping them monitor their health. It may also be useful to give the physicians an insight into the health of the patient, any side effects for any particular product. These digital services also make it easier for doctors to communicate their message to patients with ease on certain health conditions. Digital marketing has clearly simplified advertising, awareness campaign organization, and mass reach at low cost and efficient methodologies. The use of medical pharmaceuticals is worldwide dependent. Cardiovascular disorders and hypertension are at a peak in the developed nations. Although, infectious diseases such as tuberculosis typhoid, and some other diseases are prevalent in developing countries. Pharmaceutical-based companies are working hard to keep up with developments that digital technology has brought in. In recent years, the use of digital marketing in this field has allowed companies to take a different approach to targeting customers, doctors and caregivers. Some of the technologies that change the healthcare sector include mobile communications, advanced analytics, the internet and the cloud. Although most Indian companies have restricted their use in creating corporate image, updating therapy, simple diet guidelines, nutrition, exercise, etc. Nutraceuticals are slightly aggressive in their distribution with only a few firms concerned with goods in the field Over the Counter.

\section{TYPES OF DIGITAL MARKETING}

1. Search engine optimization: As consumers search the most used search engines they first turn into Google, Yahoo or MSN / Bing. Searching health information among internet users of all ages is one of the most common activities. The most popular way to find products or details is via search engines is said by 47 percent of web users. The top 10 search results receive $78 \%$ higher visitors than trailing lists, other businesses use SEO to ensure their sites are high on the list. Nearly every day, SEO approaches change. Search ranks are manipulated with the help of search engine optimisation strategies, which improve Google or any other search engine's search ranking. This is a significant opportunity to reach their target audiences with companies that use Search Engine Optimization (SE0) approaches. Organizations which are not in search engines lose a massive chance to reach the target population. The keyword use of titles and URLs, internal links from your own page, backlinks from other pages, proper use of image tags and the social network operation are important aspects of search engine optimization.

2. Pay Per Click Ads: Ads may be bought from Google if there is inadequate traffic from the company's website. Announcements are also available on other blogs and through the various ad networks. Pay-by-click or PCC adds based on the keywords used by Google's search engine. The client will determine the success rate of PPC campaigns through Ad Analytics software. The client just charges if someone clicks on the attach button.

3. Email Newsletters:The 2012 User Preference Survey by ExactTarget showed that the email is still the first direct channel that users will choose for everyday use both for customer and marketing communications. However, smartphones and tablets are commonly used and allow consumers to quickly access the emails. In fact, $77 \%$ of customers prefer to receive authorisation-based marketing messages via e-mail relative to social media $(6 \%)$ and text messages (5\%). Email gives consumers the sense of control and personalization in which to opt for a conversation and then supply them with only the information they want. 
4. Social Media Marketing: Search engines use social media activity as a marketing tool. Facebook shares, twitter retweets and Google +1 help your position on the results pages for search engines. Marketing in social media allows the company to be connected directly to its consumers. This strengthens the corporate values and improves the organization's image. In the public forum the negative experiences can be overcome through the delivery of company website alerts and debate. Modern life, including pharmaceutical marketing and the healthcare sector, is the result of social media usage. Almost all (97.8 percent) of participant participants to the study were active social network users, which coincides with the effects of social media development in the United States as defined by Moorhead et al.

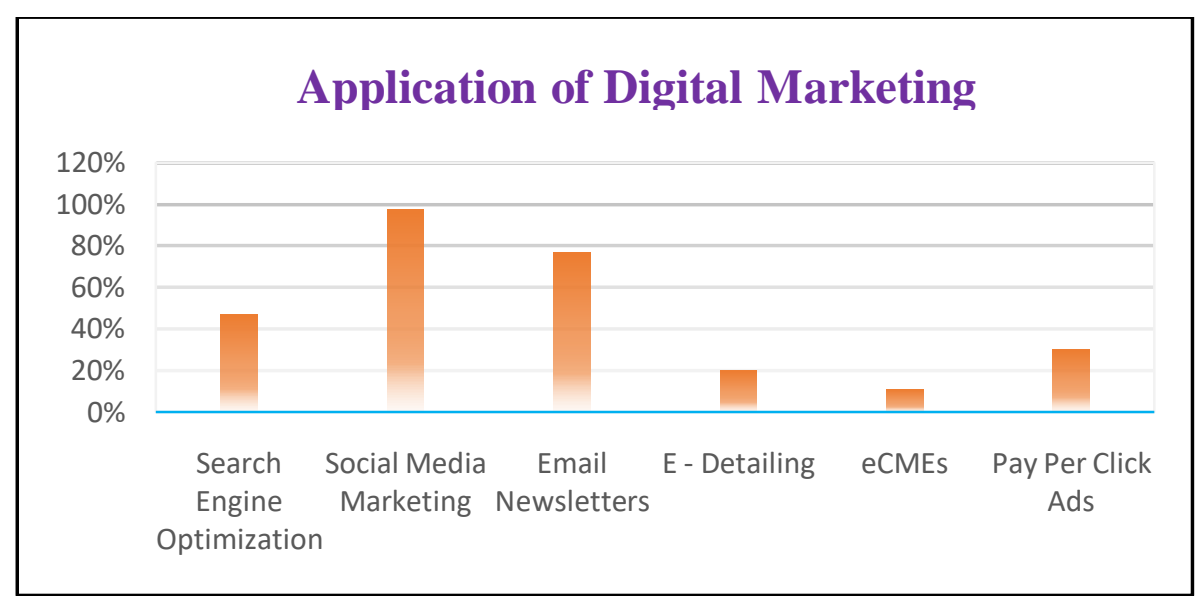

5. E - Detailing: The Indian industry has yet to be embraced at an early stage. There are very few firms that are active players on the e-detailing market in India. While e-details were initially skeptical by the sales force and they were curious whether marketing online would make the conventional sales call irrelevant, most members saw actually the opposite effect: e-details actually increase the total time they spend with the rep.

6. eCMEs (electronic continuing medical education) / WebinarsHybrid meetings are events which combine live and virtual elements. These are also great opportunities and one of the most important developments in the preparation of events. Live broadcasting by means of streaming video of a conference will enable event organizers and organizing organizations, including people following the conference online, to extend their meeting visibility. This is one of Indian Pharmaceutical Industry's most cost effective strategy.

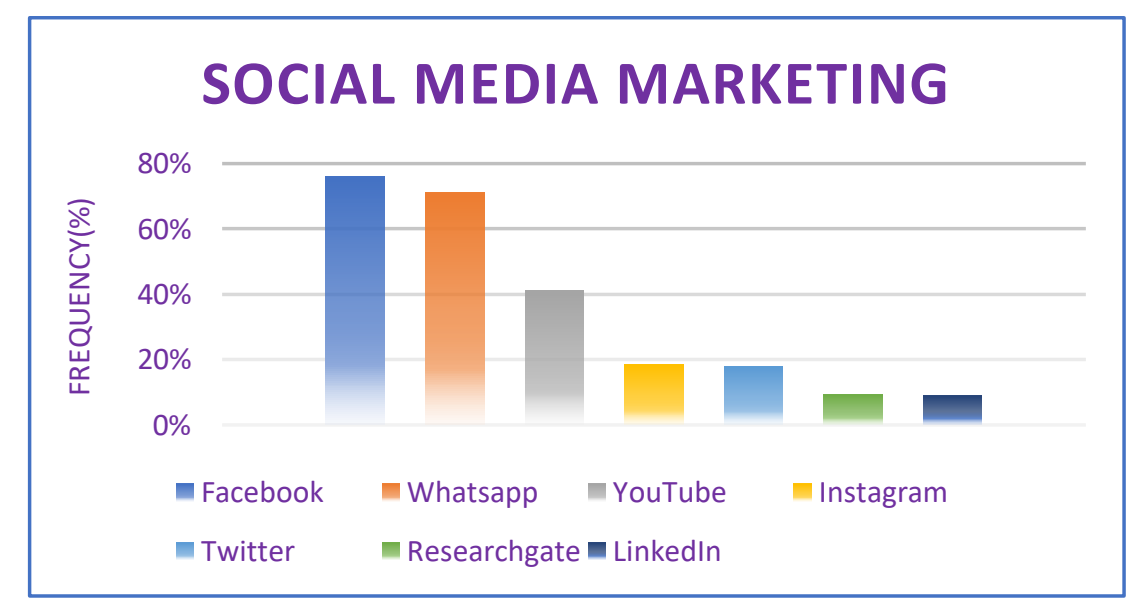




\section{CURRENT SCENARIO AND CHALLENGES:}

The numbers of approximate internet users were 4.48 billion in world in the year 2019 followed by560 million users in India and802 million users in China and increasing day by day worldwide. This has given a major boost to the digital era in various sectors.

In any sector, digital marketing is a more cost-effective and less time-consuming method of communicating with clients compared to traditional marketing. Digital marketing permits the use of data by pharmaceutical marketers to develop more strategic engagement with prescribers and physicians. Nonetheless, many companies still cannot integrate digital into the broader business strategy. The pharmaceutical sector is facing several difficulties in implementing the techniques of digital marketing some of which are discussed below.

1. Inadequate organization vision: For the introduction of digital marketing approaches, most organizations lack a proper vision. The approaches aren't clearly defined, accepted and publicly communicated. There is a need for good management to affirm the vision set goals and track the quality of operation. Identifying the field force and marketing champions that promote the digital pharmaceutical vision is usually not found in the companies.

2. A lack of digital minds: There is a lack of skilful workforce in the pharmaceutical sector that wants to drive digital change. Employees should have knowledge of digital marketing, as well as the complexities of digital adoption in the pharmaceutical industry, to develop digital marketing within the business. Most of the companies lack the efficient workforce that understands both the industry and the new digital market at the same time.

3. A digital disaster: Digital channels and campaigns have started to be implemented by many pharmaceutical companies; however, marketers in this field are unable to implement an overall effective digital strategy. Improved data contributed to complicated analyses and the use of data in digital approaches has created a global tragedy. The pharmaceutical marketers will unify data across channels; use the data in real-time, optimize digital campaigns using their digital minds accordingly.

4. Strict Regulations: The question of the regulations in each jurisdiction requires close review before any digital projects are initiated. Compared with other sectors, life sciences marketing faces stricter regulations. The pharmaceutical sector must follow the requirements of both the FDA and the Federal Trade Commission (FTC) from the privacy to the creative copy. Establishment of the Health Insurance Portability and Accountability Act (HIPAA) in 1996 secured the health data's safety and privacy. The act prohibited digital abuse of health data by advertisers, ensuring the integrity of health care records.In 2010, FDA issued a warning letter to a Novartis to pull back Facebook share, as there was inadequate risk information about the Tasigna leukaemia treatment drug. With the quest limitations the pharmaceutical companies have been more cautious about investing in new digital marketing strategies and introducing them. Industries capable of combining digital and the approval process with built-in regulatory workflows can do real-time digital work.

5. Poorly maintained websites: The use of social media by biopharmaceutical producers is sluggish. Some of the pharmaceutical companies are still following the old world of "Web 1.0." The pharmaceutical industry has chosen one-way information exchange which has been properly reviewed, lawfully accepted and shielded from external interference. These websites only move information that is unavailable in direct patient 
interaction. An out - of-date, poorly maintained site is worse than finding no site at all. Efficient human resources must find to manage these interactions.

The few strategies that can be adopted by pharmaceutical companies to increase their chances in the digital world follow.

1. Introducing mobile apps: The FDA released the guidelines on mobile medical applications, easing the pharmaceutical sector' long-term wait. Mobile applications in one go help patients to understand their diagnoses and medicines better before they are released. Apps that allow better direct marketing to customers can include complete details about any drug. If they partner with companies that can deliver the applications in context of patient management, including symptoms and medicines, not specifically disease management, pharmaceutical companies would be more profitable.

2. Collaborative business model: behind its conventional obstacles, the pharmaceutical industry is increasingly innovating by collaborating with and beyond its partners. Comprehensive collaboration is possible thanks to the availability of digital technologies. The workers can work and develop new treatments effectively and efficiently. Pfizer, for instance, has developed a ground breaking cloud-based clinical data platform to collect, interpret and visualize patient data in clinical tests through trials and medical programs and to help smart test design, precision medicine, pharmacovigilance and regulatory enquiries.

3. Sharing data on population studies: Extensive overtime data collected appears to be wasteful if not analysed. The results of the data should be reported. The combination of point, mobile and analytical content will be the real transformation in digital healthcare.

4. Ensure IT support: Adequate IT support is required to solve digital marketing problems.

5. Create a new digital marketing organizational structure: appoint a e-marketing strategy manager, e-marketing product manager, digital marketing committee, etc., to help boost company digital marketing innovation, and to develop digital strategies.

6. Business partners: Digital strategies involve partnerships with companies that deal with complimentary disease aspects. For example, companies marketing atrial fibrillation anticoagulants should partner with medical device firms that identify such patients with remote cardiac monitoring. It is not difficult to introduce a digital marketing method.

7. Patient and Healthcare Provider services (HCPs): Patient and Healthcare Provider services (HCPs) are also expected to provide patients with technology-based services that can support patients with quality monitoring and administration by using more software on a daily basis. These services can also contribute substantially to new therapies research and development. To order to support and show outcomes, it also connects partners across the broader healthcare community. Patient services that are digitally enabled, such as apps or on-line platforms or educational resources linked to a wider range, should be used to assist patients and HCPs dealing with health issues.

\section{CONCLUSION:}

People today are highly busy and spend the most of their time on android devices, laptops or digital devices. Digital marketing is important in the pharmaceutical sector, according to the available research data. Digital commercialization allows the industries to grow rapidly. It has become a strong marketing cornerstone and has encouraged and made campaign 
strategies even simpler. Only a handful of digital marketing methods are popular, and the others are in the process. All kinds of digital marketing are however easy to reach and save a lot of money, energy, time and effort. These new technologies have been introduced by pharmaceutical companies in line with the modern digitized world. Nevertheless, the adoptability of such techniques was limited to blogs, the face book account, the LinkedIn profile, etc. Although the information is poorly managed and not up to the mark. The same was also shown in our study.

\section{REFERENCE:}

1. Parekh, Dhara, Pankaj Kapupara, and Ketan Shah; 'Digital Pharmaceutical Marketing: A Review', Research Journal of Pharmacy and Technology, 9.1 (2016), 108-12

2. Friend, Simon, Steve Arlington, Todd Evans, Joseph Palo, and Anthony Farino, 'Pharma 2020: Marketing the Future', PricewaterhouseCoopers, 2009, 32

3. Kumar, Manoj, and Prof BhausahebLondhe, 'Relevance and Impact of Digital Marketing in Indian Pharmaceutical Industry with Specific Reference to Super Specialists Doctors', 7.2 (2019), 1-7

4. Sarma Ranganathan, Smitha, Vishal C Bellani, and Author Smitha Sarma Ranganathan, 'Digital Marketing in the Indian Pharmaceutical Industry: A Study To Assess Views of Pharmaceutical Marketing Professionals in Using Digital Marketing As a Brand Promotional Lever', World Journal of Pharmacy and Pharmaceutical Sciences, 5041.4 (2016), 2278-4357

5. Lalitkumar, Prof. Bhole B. Pharm, and Sushma Verma; 'Digital Marketing: A Road Ahead To Pharmaceutical Selling', 2018, 61-65

6. Dhara P, Pankaj K, Ketan S; Digital pharmaceutical marketing: a review. Res J Pharm Technol. 2016, 9:108-12. 10

7. Kaplan AM, Haenlein M: Users of the world, unite! The challenges and opportunities of social media. Business Horizons. 2010, 53:59-68.

8. Greene JA, Kesselheim AS: Pharmaceutical marketing and new social media. N Eng J Med. 2010, 363:2087-89

9. Jawaid, Masood, and Syed J Ahmed, 'Pharmaceutical Digital Marketing and Its Impact on Healthcare Physicians of Pakistan: A National Survey', Cureus, 10.6 (2018)

10. Shankar, V. and Li, J, "Leveraging Social Media in the Pharmaceutical Industry", Springer International Publishing AG, pp.477-505, 2013

11. Schultz, D. and Peltier, J, "Social Media's Slippery Slope: Challenges, Opportunities and Future Research Directions", Journal of Research in Interactive Marketing, 7(2), pp.86-99, 2013

12. Gupta, P. and Udupa, A, "Social media marketing by pharmaceutical industry: Perception and attitudes of key stakeholders", Business and Economics Journal, 2011, 1-8.

13. Shankar, V. and Li, J, "Leveraging Social Media in the Pharmaceutical Industry", Springer International Publishing AG, 477-505, 2013

14. Business Insider, "Indian pharma sector to opt for new age digital marketing, here's why", Business Insider, Available at: https://www.businessinsider.in/Indian-pharmasector-to-opt-for-new-age-digital-marketing-heres-why/ articleshow $/ 55150340 . \mathrm{cms}$

15. Jordan, A, "The 9 different types of digital marketing: Which is right for you?" Pop Content. Available at: http://popcontent.co.uk/different-types-of-digital-marketing/ 
16. Nigel Wright. Digital marketing to play greater role in the promotion of pharmaceutical companies and products? Available at:http://www.nigelwright.com/media/1036/imaginemagazine-issue-12.pdf

17. Business Insider, "Indian pharma sector to opt for new age digital marketing, here's why", Business Insider, Available at: https://www.businessinsider.in/Indian-pharmasector-to-opt-for-new-age-digital-marketing-heres-why/ articleshow/55150340.cms 